\title{
Diurnal pattern of the drying front in desert and its application for determining the effective infiltration
}

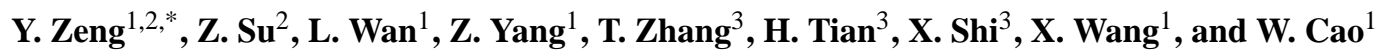 \\ ${ }^{1}$ School of Water Resources and Environment, China University of Geosciences, Beijing, China \\ ${ }^{2}$ International Institute for Geo-information Science and Earth Observation, Enschede, Netherlands \\ ${ }^{3}$ Cold and Arid Regions Environmental and Engineering Research Institute, Chinese Academy of Sciences, \\ Lanzhou, China \\ *now at: International Institute for Geo-information Science and Earth Observation, Enschede, Netherlands
}

Received: 14 January 2009 - Published in Hydrol. Earth Syst. Sci. Discuss.: 24 February 2009

Revised: 11 May 2009 - Accepted: 21 May 2009 - Published: 3 June 2009

\begin{abstract}
Located in western Inner Mongolia, the Badain Jaran Desert is the second largest desert in China and consists of a regular series of stable megadunes, among which over 70 permanent lakes exist. The unexpected lakes in desert attracted research interests on exploring the hydrological process under this particular landscape; however, a very few literatures exist on the diurnal and spatial variation of the drying front in this area, which is the main issue in the desert hydrological process to characterize the movement of water in soil. In order to understand the drying front in the Badain Jaran Desert, a field campaign was conducted by the observations of soil physical parameters and micrometeorological parameters. With the field data, the performance of a vadose zone soil water balance model, the HYDRUS, was verified and calibrated. Then, the HYDRUS was used to produce the spatial and temporal information of coupled water, water vapour and heat transport in sand to characterize the variation pattern of the drying front before, during and after the rainfall. Finally, the deepest drying front was applied to determine the effective infiltration, which is defined as the amount of soil water captured by the sand beneath the deepest drying front by infiltrating water of an incident rainfall event.
\end{abstract}

\section{Introduction}

Infiltration has long been regarded as one of the most difficult problems for hydrological forecasting, due to its relevance to runoff, soil moisture storage, evapotranspiration, ground-

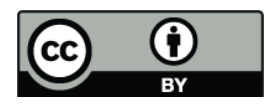

Correspondence to: Y. Zeng

(yijian@itc.nl) water recharge and unsaturated flow (Ghildyal and Tripathi, 1987; Mitkov et al., 1998; Tami et al., 2004). Its significance on assessing the hydrological process in the desert environment, which is the main plant community shaping process in arid ecosystems, is even magnified. In desert, the precipitation is often the solo source of water replenishment, while the infiltration is the main process to understand how much rainfall could be retained in sand for some time before being either passed downward as percolation or returned to the atmosphere by the process of evapotranspiration.

In water scarce regions, demonstrating whether modern rainfall is recharging aquifers through infiltration and on what rate or scale is one of the main issues facing scientific society. The Badain Jaran Desert with unexpected numerous groundwater-fed perennial lakes has attracted substantial research interest on the desert hydrological process, and the infiltration in this special landscape, lakes in inter-dune areas (Gu et al., 2006; Walker et al., 1987), has been widely studied. Hofmann $(1996,1999)$ stated there was an aquifer in the northern areas of the eastern lakes region, recharged directly by precipitation through infiltration process, while he did not study the infiltration rate. Based on hydrochemical and isotopic analysis, $\mathrm{Gu}$ (2006) points out that groundwater flows from adjacent areas in the south to the northwestern part with a historic and fossil recharge (1000 to $30000 \mathrm{BP}$ ); and with the actual analytical results on groundwater chlorides, he estimates that 1 to $1.5 \mathrm{~mm} / \mathrm{yr}$ of groundwater recharge would occur by direct infiltration from precipitation. With the tracer methods, more and more recharge rate data are reported and added to a growing catalogue of tracer results for the Badain Jaran Desert region, which leads to the estimated average recharge rate in this region varies from 0.95 to $3.6 \mathrm{~mm} / \mathrm{yr}$ (Geyh et al., 1996; Hofmann, 1996; Ma et al., 2003; Ma

Published by Copernicus Publications on behalf of the European Geosciences Union. 
and Edmunds, 2006; Yang, 2006; Yang and Williams, 2003b; Zhang and Ming, 2006; Chen et al., 2004; Gates et al., 2006, 2008b; Jakel, 1996).

Afore mentioned studies are mainly focused on the rate at which the infiltrated rainfall recharges the groundwater, which could be called the effective infiltration or the effective rainfall (Wu et al., 1997; Bonacci et al., 2006). However, the effective infiltration or rainfall could also be defined as the amount of rainfall stored in the shrub root zone, excluding the fraction that runs off the soil surface or passes through the root zone that does not contribute to shrub growth and the fraction that evaporates (Wang et al., 2007). From above two definitions, obviously, the effective infiltration or rainfall could be generally defined as the portion of rainfall that penetrates and remains in a domain of interest. With this general definition, in this study, the effective infiltration is the amount of soil water remained in sand beneath the drying front (marking the interface between the upwards and downwards soil water fluxes) by infiltrating water of a rainfall event, and thus not evaporated, and is evaluated based on the vadose zone soil water balance method.

As what mentioned above, the estimates of infiltration rate in desert have been conducted a lot with the tracer method, which is mainly used to evaluate variations of flow and transport in thick desert vadose zones in response to paleoclimatic forcing, and thus with the time scale of thousand-year (Scanlon et al., 2003). While with the soil water balance model, the infiltration and soil water redistribution process in the unsaturated zone could be tracked at any meaningful time scale of interest. In order to do that, quantifying changes in infiltration properties by a reliable observation and measurement is needed. Previous studies has indicated the feasibility of using soil water content probes installed into the soil to track the propagation of the wetting front during infiltration (Topp et al., 1982; Noborio et al., 1996; Timlin and Pachepsky, 2002; Melone et al., 2006; Tami et al., 2004; Yang 2004, 2006; Wang et al., 2007, 2008; Geiger and Durnford, 2000), and, therefore, to track the drying front during evaporation.

In this study, the measurements of soil water content, soil temperature and precipitation were used to verify and calibrate the performance of a vadose zone soil water balance model, the HYDRUS, which was subsequently used to produce the temporal and spatial information of coupled water, water vapor and heat transport. This enabled us to characterize the variation pattern of the drying front before, during and after rainfall, so that we could assess how much precipitation is evaporated and how much is conserved in sand. Our goal was to understand the capacity of the sand dune to capture certain amount of rainfall during a single precipitation event, which is available to plants. The first section of the paper thus describes the experiments and methods used. Then follows simulation results based on experimental observations. Finally, we conclude the paper with a discussion of practical results.

\section{Materials and methods}

\subsection{Study site description}

The study site is a relatively flat area at the foot of dunes, with an area of about 100 square meters, located in the southeast Badain Jaran Desert, which lies in the northwest of the Alashan plateau in western Inner Mongolia of China, between $39^{\circ} 20^{\prime} \mathrm{N}$ to $41^{\circ} 30^{\prime} \mathrm{N}$ and $100^{\circ} \mathrm{E}$ to $104^{\circ} \mathrm{E}$. The Badain Jaran Desert is regarded as the second largest desert in China, and covers an area of about $49000 \mathrm{~km}^{2}$ (Yang, 2001). The desert landscape primarily consists of unvegetated or sparsely vegetated aeolian sand dune fields as a core, surrounded by desert plains, with pediments on the margin (Yang et al., 2003a). The elevation ranges from $1500 \mathrm{~m}$ in the southeast to $900 \mathrm{~m}$ above sea level in the northwest, with the mega dunes up to $400 \mathrm{~m}$ high in the southeast aligned in a SW-NE pattern (Dong et al., 2004). The mean grain size of the dune sand in this desert is between $0.21 \mathrm{~mm}$ and $0.22 \mathrm{~mm}$ (Jakel, 1996; Yang and Williams, 2003b). There are over 70 lakes in the interdune areas, of which the surface area vary from $0.2 \mathrm{~km}^{2}$ on the southeastern edge of the desert to $1.6 \mathrm{~km}^{2}$ slightly northwards, and the water depth from $2 \mathrm{~m}$ to $16 \mathrm{~m}$ (Yang and Williams, 2003b). On the surface, there is neither recharging into these lakes nor discharging from them, and there is no river in the entire desert (Yang, 2001; Wang and Cheng, 1999). With such hydrological conditions, vegetation in the study area is sparse. The plant or shrub communities depend mainly on the geomorphology and on edaphic conditions. The dominant plant species are Haloxylon ammodendron, Psammochoa villosa, Phragmites communis, Artemisia ordosica, while in the area around lakes and springs the denser groundcover observable could be found (Polypogon monspeliensis, Triglochin maritima, Achnatherum splendens, Carex sp., Glaux maritima) (Gates et al., 2008a).

The distribution of sparse vegetation in this area is mainly caused by the dominated climate pattern in the Alashan Plateau, which is characterized by a markedly arid and continental climate. During the winter months, a well-developed high pressure system, cold and dry continental air masses with temperatures below zero, influences the area, which caused the mean monthly temperature in January become $-10^{\circ} \mathrm{C}$. In the summer months, the tropical air masses from the Pacific Ocean hits the Badain Jaran Desert with more than half of the average annual precipitation fell in July. The spatial and temporal distribution of the precipitation in the area is determined by the Asian summer monsoons at the present time, and the mean monthly temperatures in July is $25^{\circ} \mathrm{C}$ with a diurnal temperature variation up to more than $45^{\circ} \mathrm{C}$. The mean annual precipitation varies from 84 to $120 \mathrm{~mm}$ in the southeast, and from 37 to $40 \mathrm{~mm}$ in the northwest, and the potential evaporation is approximately $2600 \mathrm{~mm} / \mathrm{yr}$, being the highest in China (Ma et al., 2003; Ma and Edmunds, 2006; Gates et al., 2008a). 


\subsection{Experimental design and data collection}

In order to quantify the effective infiltration, measurements of soil water content, temperature and matric potential were conducted in the observation period, from 3 June to 20 June in 2008. The instruments used for measuring soil moisture and temperature are the profile sensors using numerous of transducers combined in one probe with a certain distance interval between them. It is especially necessary to use the profile sensor in desert, considering the sand profile would collapse easily during digging. As for the soil matric potential, there was not a profile sensor available and four separate transducers, $\mathrm{pF}$-meters (GeoPrecision $\mathrm{GmbH}$, Ettlingen, Germany), were installed at the corresponding depth of soil water content monitoring.

The soil water content profile sensor was called as EasyAG50 (Sentek Pty. Ltd., Stepny, South Australia), the principles of operation and design of which were described in detail by Fares and Polyakov (2006) and the manufacture's calibration manual (Sentek Pty. Ltd., 2001). An individual EasyAG50 consisted of a printed circuit board, five capacitance sensors, and a polyvinyl chloride (PVC) access tube with external and internal diameters of 32 and $28 \mathrm{~mm}$, respectively. Capacitance sensors were set at 10, 20, 30, 40, and $50 \mathrm{~cm}$ from the sand surface. The reading range of these capacitance sensors was from oven dry to saturation. The correlation coefficient between the readings and actual soil water content based on field calibration was $89.39 \%$, with a resolution of $0.008 \%$, and a precision of $\pm 0.06 \%$. The temperature effects on readings of MCP (Multi-sensor Capacitance Probe) were conducted in the lab with the standard procedures described in detail by Polyakov (2005) and Fares (2007). The temperature effects for the capacitance sensors were $14.4 \%$ of readings from $12^{\circ} \mathrm{C}$ to $45^{\circ} \mathrm{C}$ at $10 \mathrm{~cm}$, $13.9 \%$ from $11^{\circ} \mathrm{C}$ to $50^{\circ} \mathrm{C}$ at $20 \mathrm{~cm}, 14 \%$ from $9^{\circ} \mathrm{C}$ to $51^{\circ} \mathrm{C}$ at $30 \mathrm{~cm}, 13 \%$ from $9^{\circ} \mathrm{C}$ to $55^{\circ} \mathrm{C}$ at $40 \mathrm{~cm}$, and $15 \%$ of readings from $8^{\circ} \mathrm{C}$ to $55^{\circ} \mathrm{C}$ at $50 \mathrm{~cm}$, respectively. After the calibration, the temperature effects at the depth of $10,20,30$, 40 , and $50 \mathrm{~cm}$ were reduced by $92 \%, 93 \%, 93.8 \%, 88 \%$, and $82 \%$, respectively.

The soil temperature profiles were measured by STP01 (Hukseflux Thermal Sensors B.V., Delft, the Netherlands), which was designed to measure the soil temperature at specific depths by determining the thermal gradients between a certain specific depth and the reference point. It improved the accuracy in positioning, the uncertainty of which was usually large when using a series of separate sensors. This made the temperature gradient measurement more correctly, which subsequently improved the accuracy of the absolute temperature measurement. The principles of measurement by STP01 had been described in detail by the manufacture's manual (Hukseflux Themal Sensors, 2007). A single probe generally contained five thermocouples, a copper lead, a Pt 100, a TC junctions and a sensor foil with the thickness of $0.6 \mathrm{~mm}$. The thermocouples were set at $2,5,10,20$, and $50 \mathrm{~cm}$ from the sand surface. The measurement range of STP01 was from $-30^{\circ} \mathrm{C}$ to $70^{\circ} \mathrm{C}$, with an accuracy of $\pm 0.02^{\circ} \mathrm{C}$.

During installation, a single MCP probe (soil water content profile sensor) was inserted into a $60-\mathrm{cm}$-long access, which would be put into a pit with sufficient width and depth. The probe was inserted into the sand through the side of the pit that was unaltered and was placed vertically to the sand surface. At the same time, about $30 \mathrm{~cm}$ away from $\mathrm{MCP}$ probe on the same side of the pit, the STP01 (soil temperature profile sensor) was installed vertically with the aid of a steel ruler, considering the sensor foil was too soft to be inserted in sand directly. After the set up of MCP and STP01 probe, the pit was carefully refilled, avoiding perturbations as far as possible. During the refilling, the separate soil matric potential sensors, $\mathrm{pF}$-meters, were also inserted vertically on the same side of the pit where the two probes were installed, at the depth of $50,40,30$ and $20 \mathrm{~cm}$ from the sand surface. The $\mathrm{pF}-$-meter was based on the registration of the molar heat capacity of the ceramic cup, which was in contact with the soil for balance, to record the matric potential over a large measurement range from $\mathrm{pF} 0$ to $\mathrm{pF} 7.0$, with an accuracy of $\pm \mathrm{pF} 0.05$, an precision of less than $\pm \mathrm{pF} 0.015$, and a resolution power of $\mathrm{pF} 0.01$. The site was set up at the end of May 2008 and measurements were not begun until one week later to allow the repacking sand to settle down.

The precipitation was measured using a tipping bucket rain gauge, model TR-5251 (RST Instruments Ltd., Coquitlam, Canada), with a precision of $\pm 0.01 \mathrm{~mm}$ and a resolution of $0.01 \mathrm{~mm}$. At the same time, other micrometeorological parameters such as the air temperature, relative humidity, net radiation and wind velocity at a height of $2 \mathrm{~m}$ above the surface layer were also measured. Two data collection and processing systems CR1000 and CR5000 (Campbell Scientific Inc., Logan, Utah, USA) were used to record the field data at half-hourly intervals. The first one was used to record the soil physical parameters, while the second one for the micrometeorological parameters.

\subsection{Soil water balance model}

\subsubsection{Model description}

The HYDRUS1D code, which refers to the coupled water, vapour and heat transport in soil was applied in order to determine the temporal and spatial soil water fluxes. The governing equation for one-dimensional vertical flow of liquid water and water vapour in variably saturated media is given by the following mass conservation equation (Saito et al., 2006):

$\frac{\partial \theta}{\partial t}=-\frac{\partial q_{L}}{\partial z}-\frac{\partial q_{v}}{\partial z}$

Where, $q_{L}$ and $q_{v}$ are the flux densities of liquid water and water vapour $\left(\mathrm{cm} \mathrm{d}^{-1}\right)$, respectively; $t$ is time $(\mathrm{d}) ; z$ is the vertical axis positive upward $(\mathrm{cm})$. 
The flux density of liquid water, $q_{L}$, is defined as (Philip and De Vries, 1957)

$q_{L}=q_{L h}+q_{L T}=-K_{L h}\left(\frac{\partial h}{\partial z}+1\right)-K_{L T} \frac{\partial T}{\partial z}$

Where, $q_{L h}$ and $q_{L T}$ are, respectively the isothermal and thermal liquid water flux densities $\left(\mathrm{cm} \mathrm{d}^{-1}\right) ; h$ is the matric potential head $(\mathrm{cm}) ; T$ is the temperature $(\mathrm{K})$; and $K_{L h}$ $\left(\mathrm{cm} \mathrm{d}^{-1}\right)$ and $K_{L T}\left(\mathrm{~cm}^{2} \mathrm{~K}^{-1} \mathrm{~d}^{-1}\right)$ are the isothermal and thermal hydraulic conductivities for liquid-phase fluxes due to gradients in $h$ and $T$, respectively.

Using the product rule for differentiation and assuming the relative humidity in soil pores being constant with temperature (Philip and De Vries, 1957), the flux density of water vapour, $q_{v}$, can be written as

$q_{v}=q_{v h}+q_{v T}=-K_{v h} \frac{\partial h}{\partial z}-K_{v T} \frac{\partial T}{\partial z}$

Where, $q_{v h}$ and $q_{v T}$ are the isothermal and thermal water vapour flux densities $\left(\mathrm{cm} \mathrm{d}^{-1}\right)$, respectively; $K_{v h}\left(\mathrm{~cm} \mathrm{~d}^{-1}\right)$ and $K_{v T}\left(\mathrm{~cm}^{2} \mathrm{~K}^{-1} \mathrm{~d}^{-1}\right)$ are the isothermal and thermal vapour hydraulic conductivities for water vapour, respectively. Combining Eqs. (1), (2), and (3), we obtain the governing liquid water and water vapour flow equation:

$\left[\frac{\partial \theta}{\partial t}=\frac{\partial}{\partial z}\left[K_{L h} \frac{\partial h}{\partial z}+K_{L h}+K_{L T} \frac{\partial T}{\partial z}+K_{v h} \frac{\partial h}{\partial z}+K_{v T} \frac{\partial T}{\partial z}\right]\right]$

$=\frac{\partial}{\partial z}\left[K_{T h} \frac{\partial h}{\partial z}+K_{L h}+K_{T T} \frac{\partial T}{\partial z}\right]$

Where, $K_{T h}\left(\mathrm{~cm} \mathrm{~d}^{-1}\right)$ and $K_{T T}\left(\mathrm{~cm}^{2} \mathrm{~K}^{-1} \mathrm{~d}^{-1}\right)$ are the isothermal and thermal total hydraulic conductivities, respectively, and:

$$
\begin{aligned}
& K_{T h}=K_{L h}+K_{v h} \\
& K_{T T}=K_{L T}+K_{v T}
\end{aligned}
$$

For the sake of brevity, detailed description of the HYDRUS1D code is not given here. But any interested readers are referred to Saito et al. (2006).

\subsubsection{Material properties}

For the hourly time scale, the most active layer for the coupled liquid water, water vapor and heat in sand was near the surface and usually was limited in the depth of less than $50 \mathrm{~cm}$ (Zeng et al., 2008), which was also the frequent influence depth of a typical rainfall in the desert environment (Wang et al., 2007; Wang et al., 2008). In the field site, we sampled sand at the depth of $10,20,30,40$, and $50 \mathrm{~cm}$, respectively; and all samples were used for basic soil tests and soil water characteristic curves determinations (see later for details). It was found that the test results for these five samples were close to each other, and the deviation from the averaged value was less than $\pm 1 \%$. Then, the final results of

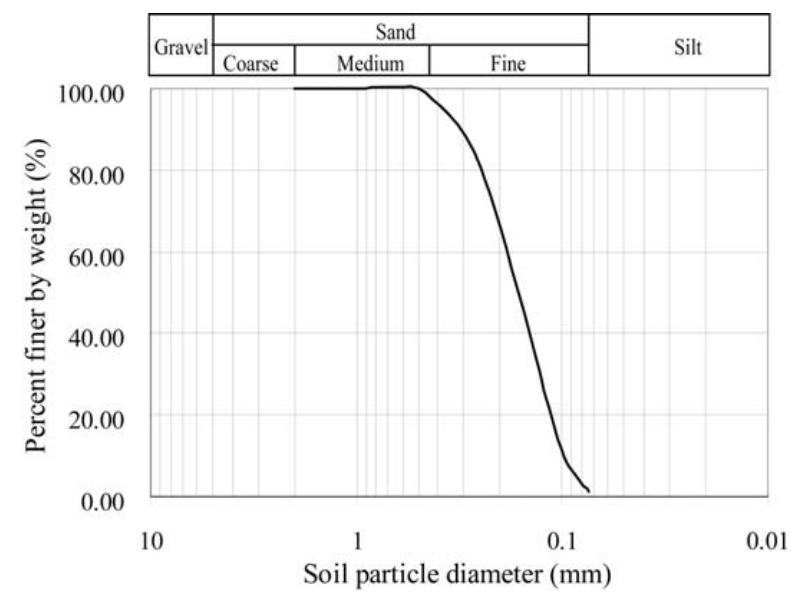

Fig. 1. Particle size distribution curve.

the material properties were derived by averaging the results of these samples.

The field site consisted of fine type sand, the grain-size distribution of which was determined and classified following the Specification of Soil Test (SST) using sieve analysis method (NJHRI, 1999). The fine sand has a coefficient of uniformity of 2.072, and a coefficient of curvature of 0.998. The particle-size distribution curve of the fine sand was shown in Fig. 1.

The soil water retention curve was one of the most fundamental hydraulic characteristics to solve the flow equation of water in soils, describing the relationship between volumetric water content and matric potential (i.e., the suction head) in the soils. According to the field measurement, the volumetric water content and matric potential data pairs $(\theta-h$ pairs $)$ at all measured depths were pooled in Fig. 2a. For every single depth, there was a different pattern, especially at the depth of $50 \mathrm{~cm}$. The data points highlighted by the oval-shaped curve were recorded after the occurrence of rainfall. These points indicated that there were phenomena of hysteresis, which meant that the soil undergoing drying processes such as evaporation or gravity drainage generally tends to retain a greater amount of water than for the same magnitude of suction during wetting processes such as infiltration or capillary rise (Lu and Likos, 2004). The data points in the oval-shaped curve represented the wetting process of the sand after the rainfall, which did not follow the drying process (data points outside the oval-shaped curve) before the rainfall. At the depth of $50 \mathrm{~cm}$, the hysteresis phenomena were more conspicuous than those at other depths. It was because hysteresis was less pronounced near the residual water content where pore water retention felt within the pendular regime (Lu and Likos, 2004). Due to the complicated hysteresis pattern, which was beyond the scope of this study, it was difficult to use the inverse method to get the van Genuchten's parameters using the in situ $\theta-h$ data pairs 
(Zeng et al., 2008). Instead, the pressure extraction chamber, model 1600 (Soil Moisture Equipment Corp., Santa Barbara, CA), was used to determine the water-holding characteristics with the soil water retention equation, which was given by (van Genuchten, 1980)

$\theta(h)=\left\{\begin{array}{cc}\theta_{r}+\frac{\theta_{s}-\theta_{r}}{\left[1+|\alpha h|^{n}\right]^{m}} & h \leq 0 \\ \theta_{s} & h>0\end{array}\right.$

where, $\theta$ is the volumetric water content $\left(\mathrm{cm}^{3} \mathrm{~cm}^{-3}\right)$ at pressure head $h(\mathrm{~cm}) ; \theta_{r}$ and $\theta_{s}$ are the residual and saturated water contents, respectively $\left(\mathrm{cm}^{3} \mathrm{~cm}^{-3}\right) ; \alpha\left(>0\right.$, in $\left.\mathrm{cm}^{-1}\right)$ is related to the inverse of the air-entry pressure; $n(>1)$ is a measure of the pore-size distribution affecting the slope of the retention function $(m=1-1 / n)$.

The comparison between the in situ $\theta-h$ data pairs and the van Genuchten model curve (determined by the pressure extraction chamber) was shown in Fig. 2b. The good agreement was found at low water content level, while the model fitted only part of the data at the depth of $50 \mathrm{~cm}$, which was due to the pronounced hysteresis in moist sand (Lu and Likos, 2004). The part of unfitted data represented the drying process of sand at the depth of $50 \mathrm{~cm}$. Considering the scope of this study was on the determination of effective rainfall, the data of interest at $-50 \mathrm{~cm}$ depth would be located at the wetting process, which were fitted well by the van Genuchten model, with $\theta_{r}=0.017 \mathrm{~cm}^{3} \mathrm{~cm}^{-3}, \theta_{s}$ $=0.382 \mathrm{~cm}^{3} \mathrm{~cm}^{-3}, \alpha=0.00236 \mathrm{~cm}^{-1}$, and $n=3.6098$ (Fig. 2b). The hysteretic behaviour in the soil water retention curve should be understood, due to its consequent impact on the stress, strength, flow and deformation behaviour of unsaturated soil systems. However, this issue was beyond the scope of this study and will not be discussed here, and any interested readers are referred to Lu and Likos (2004).

\subsubsection{Initial and boundary conditions}

Considering the groundwater table was at a depth of more than $2 \mathrm{~m}$ (Gates et al., 2008b), the soil profile was considered to be $100 \mathrm{~cm}$ deep and the bottom condition for this profile was regarded as free drainage, and the nodes located at depths of $2 \mathrm{~cm}, 5 \mathrm{~cm}, 10 \mathrm{~cm}, 20 \mathrm{~cm}, 30 \mathrm{~cm}, 40 \mathrm{~cm}$ and $50 \mathrm{~cm}$ were selected for comparing calculated temperatures and volumetric water contents with measured values. The spatial discretization of $1 \mathrm{~cm}$ was used, leading to 101 nodes across the profile. The calculations were performed for a period of 17.6 days from 3 to 20 June in 2008. Discretization in time varies between a minimum and a maximum time-step, controlled by some time-step criterion (Saito et al., 2006). Except for the aforementioned geometry and time information, it is necessary to specify initial conditions for temperature and soil water content in order to solve this problem by HYDRUS1D.

The initial soil water content and temperature distributions across the profile were determined from measured values on

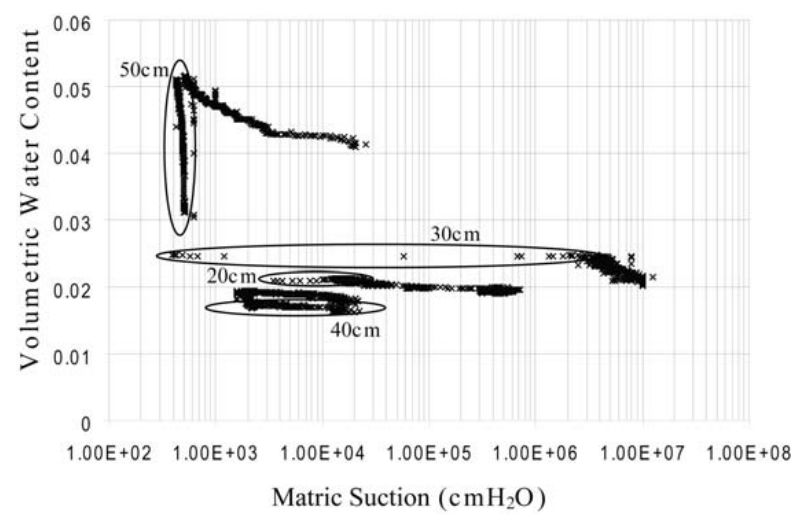

(a)

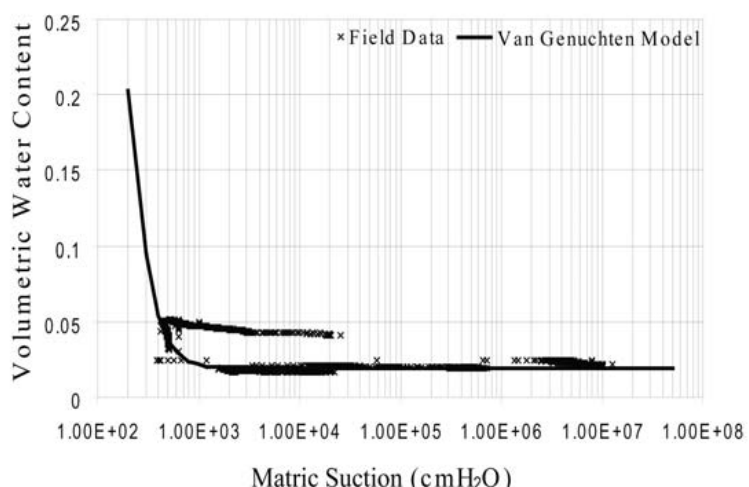

(b)

Fig. 2. The field measurement of the soil matric potentials (a) and the fitted results (b).

3 June by interpolating the measured values between two adjacent depths. Boundary conditions at the soil surface for liquid water, water vapor and heat were determined from the surface energy balance equation (e.g., van Bavel and Hillel, 1976):

$R_{n}-H-L E-G=0$

where $R_{n}$ is the net radiation, $H$ is the sensible heat flux density, $L E$ is the latent heat flux density, $L$ is the latent heat, $E$ is the evaporation rate, and $G$ is the surface heat flux density. Net radiation (e.g., Brutsaert, 1982) and sensible heat flux (e.g. van Bavel and Hillel, 1976) were defined as:

$R_{n}=\varepsilon_{s} \varepsilon_{a} \sigma T_{a}^{4}-\varepsilon_{s} \sigma T_{s}^{4} ; \quad H=C_{a} \frac{T_{s}-T_{a}}{r_{H}}$

where $\varepsilon_{a}$ is the emissivity of the atmosphere, $\varepsilon_{s}$ is the emissivity of the bare soil, $\sigma$ is the Stefan-Bolzmann constant, $T_{a}$ is the air temperature, $T_{s}$ is the soil surface temperature, $C_{a}$ is the volumetric heat capacity of air, and $r_{H}$ is the aerodynamic resistance to heat transfer. The surface evaporation is calculated as

$E=\frac{\rho_{v s}-\rho_{v a}}{r_{v}+r_{s}}$ 
where $\rho_{v s}, \rho_{v a}$ are the water vapor density at the soil surface and the atmospheric vapor density, respectively; $r_{v}, r_{s}$ are the aerodynamic resistance to water vapor flow and the soil surface resistance to water vapor flow that acts as an additional resistance along with aerodynamic resistance, respectively (Camillo and Gurney, 1986). As for the heat transport domain, the upper boundary condition was determined by the measured surface temperature, while the lower boundary condition was considered as zero temperature gradient (Saito et al., 2006).

\section{Results and discussion}

The physics of infiltration has been developed and improved during the last almost seven decades. The numerical models play a critical role in evaluating this physical process, that governing soil heating, spatial distribution of water, and gaseous exchange between the soil and the atmosphere (Melone et al., 2006; Geiger and Durnford, 2000; Mitkov et al., 1998; Shigeru et al., 1992). The most widely used model is the Richards' equation, which has been modified into the HYDRUS1D considering the coupled liquid water, vapor and heat transport. With the soil hydraulic properties and the initial and boundary conditions introduced above, the HYDRUS1D was calibrated with the field data, which was subsequently used to calculate and analyze the detailed information of the soil water flow processes under an incident rainfall event.

\subsection{Model verification}

In this section, the measured water contents and soil temperatures were compared to those calculated by the HYDRUS1D code, which refers to the coupled liquid water, water vapor and heat transport in soil. The predicted and observed soil temperatures at depths of $2,5,10,20$, and $50 \mathrm{~cm}$ were shown in Fig. 3. The simulation's goodness of fit was quantified with the following relative root mean square error measure:

RRMSE $=\frac{\sqrt{\sum_{i=1}^{N_{W}}\left(M_{i}-C_{i}\right)^{2} / N_{w}}}{\operatorname{Max}\left(M_{1}, M_{2}, \ldots \ldots, M_{N_{w}}\right)-\operatorname{Min}\left(M_{1}, M_{2}, \ldots \ldots, M_{N_{w}}\right)}$

where, $N_{w}$ is the number of the measurements; $M_{i}$ and $C_{i}$ are measurements and calculations, respectively; $\quad \operatorname{Max}\left(M_{1}, M_{2}, \ldots \ldots, M_{N_{w}}\right) \quad$ and $\operatorname{Min}\left(M_{1}, M_{2}, \ldots \ldots, M_{N_{w}}\right)$ are the maximum and minimum value of the measurements. The RRMSE is dimensionless and RRMSE $=0$ indicates the best fit. The smaller is the RRMSE, the better the fit of simulation.

The RRMSEs of the temperatures at depths of $2,5,10$, 20 , and $50 \mathrm{~cm}$ were, respectively $0.063,0.061,0.096,0.183$, and 0.17. Although the RRMSEs of the fitness at the depth of 20 and $50 \mathrm{~cm}$ were larger than 0.1 and close to 0.2 , which

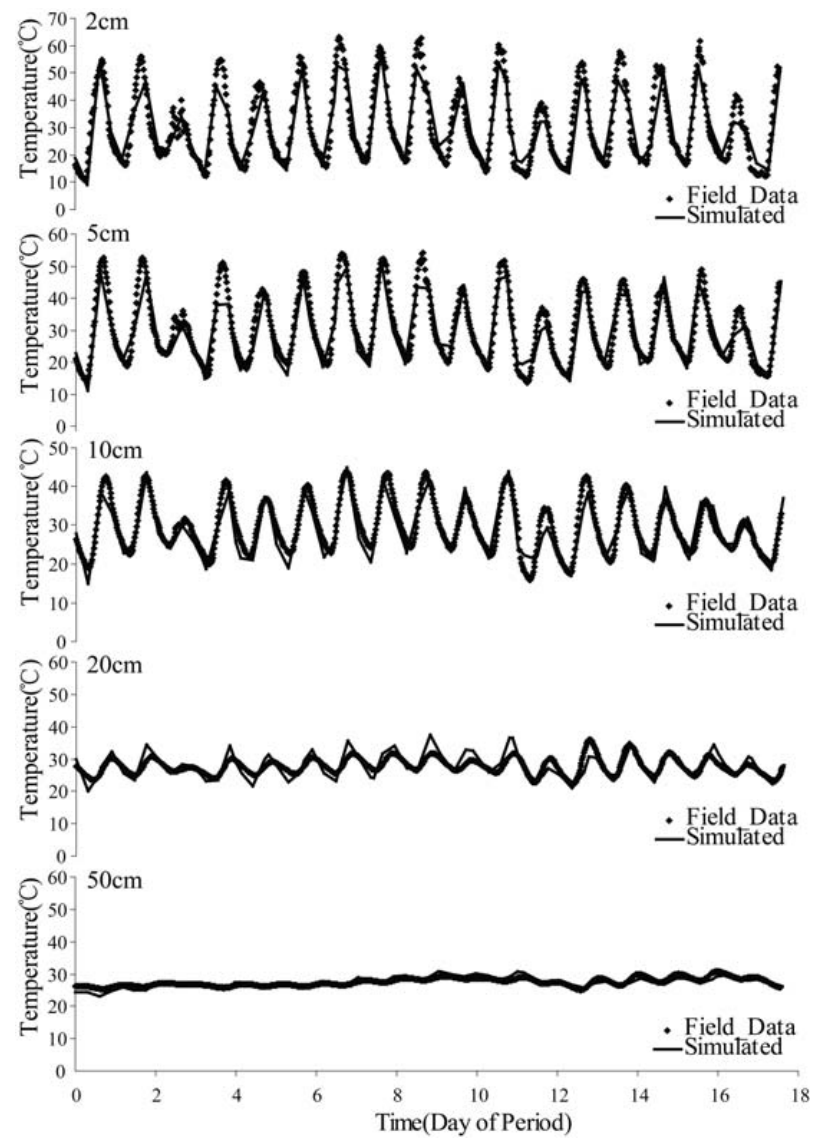

Fig. 3. The calculated and measured soil temperature at all depths.

means the largest deviation were $-6^{\circ} \mathrm{C}$ and $2.3^{\circ} \mathrm{C}$ at respective depth, the calculated and measured temperature generally agreed at all five depths and the typical sinusoidal diurnal variation of soil temperature were captured.

During the field monitoring, an incident precipitation was captured. The evaporation after rainfall was an exponential function of elapsed time ( $\mathrm{Li}$ et al., 2006), which was used in the calculation of soil moisture variation in HYDRUS1D. The simulated and measured soil water content at the depths of 10 and $20 \mathrm{~cm}$ was depicted in the Fig. 4, while the simulated results for the soil moisture at the depths of 30,40, and $50 \mathrm{~cm}$ were not shown here, which kept almost the same value during the period of field measurement. The RRMSEs of the soil water content at the depths of $10 \mathrm{~cm}$ and $20 \mathrm{~cm}$ were 0.048 and 0.19 , respectively. Both temperature and soil water content were simulated well by using HYDRUS1D.

\subsection{Determination of the drying front}

The drying front is defined as the interface between the upwards and downwards soil water fluxes. In order to understand the variation of drying front in soil, the detailed soil water content and temperature variability were shown as the 


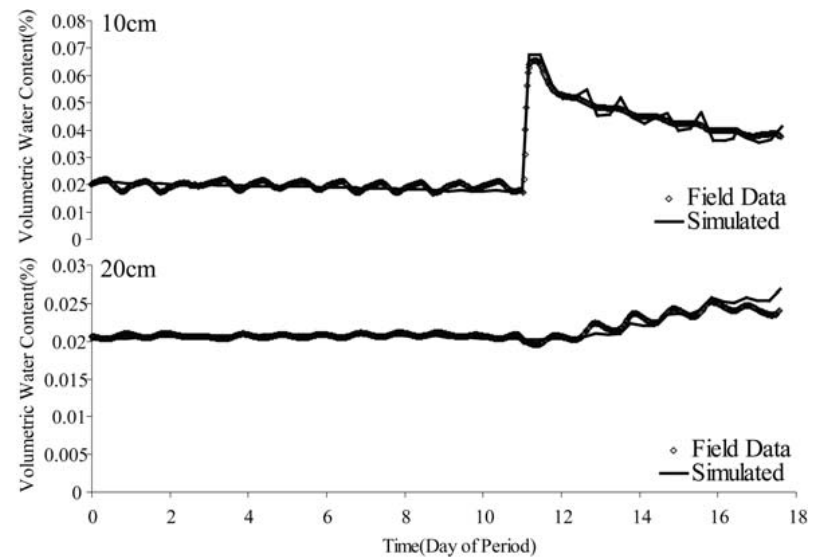

Fig. 4. The calculated and measured soil moisture content at the depth of $10 \mathrm{~cm}$ and $20 \mathrm{~cm}$.

projections of the relative altitude coordinates ( $Z$-axis) to constant depth coordinates ( $Y$-axis) and elapsed time coordinates ( $X$-axis). The interpolating and smoothing procedure for projected soil water and temperature data were carried out by using the Surfer plotting software (Golden Software, 1990). The interpolation was done using the kriging option in Surfer. The fake three dimensional fields, consisting of a space-time field (two-dimensional field) and a dependent altitude variable (e.g. specific flux, temperature or soil matric potential) (Zeng et al., 2008), were plotted to understand the time series information of specific flux, soil temperature and soil matric potential for the whole soil profile, which presented a clear overview on the physical flow processes in soil.

\subsubsection{The driving force}

The driving forces causing flow in soil are inter-dependent, for example, as temperature gradients are accompanied by gradients of surface tension at the air-water interface, there is a possibility of thermal capillary flow and thermal capillary film flow of water in liquid phase (Ghildyal and Tripathi, 1987). There is a need to identify the soil matric potential and temperature pattern for the coupled flow processes.

Figure 5a shows daily time series of soil matric potential profile during the calculation period (from 3 June to 20 June in 2008). On the day before the rainfall, the potential varied radically in the surface layer with a thickness of about $2 \mathrm{~cm}$, from $-10556.4 \mathrm{~cm}$ to $-1049.89 \mathrm{~cm}$ water column. While in the sand layer between the depth of $5 \mathrm{~cm}$ and $20 \mathrm{~cm}$, a low potential zone developed with the lowest value of $-31932 \mathrm{~cm}$ water column at the depth of $15 \mathrm{~cm}$. It meant that the soil water above and below this zone would be transported toward this low potential layer due to the convergent potential gradients, because the potential gradients above and below certain depth were directed to this depth and formed a convergent zero soil matric potential gradient

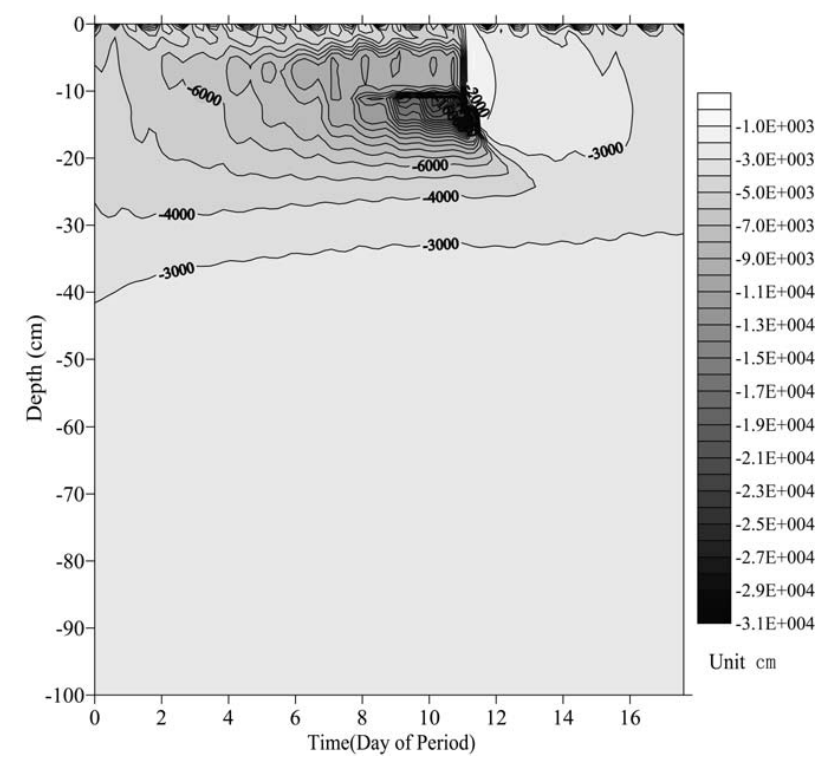

(a)

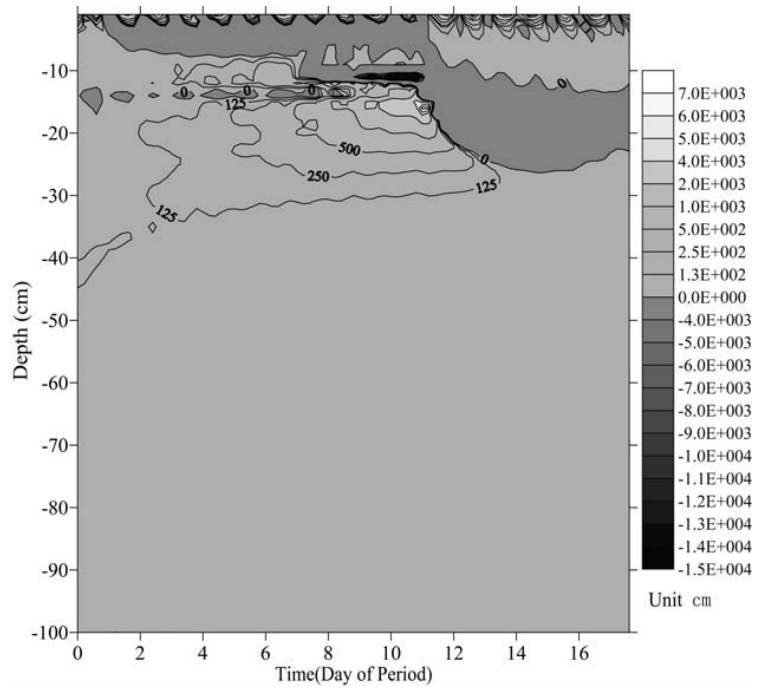

(b)

Fig. 5. The time series of soil matric potential profile (a) and its gradient profile (b).

plane (Fig. 5b). The potential gradients were decided by $\Delta h=\left(h_{i+1}-h_{i}\right)(\mathrm{cm} / \mathrm{cm})$, where $h_{i}$ represents the soil matric potential at a depth of $i \mathrm{~cm}$.

After rainfall, the pattern of the soil matric potential was totally changed. The rainfall broke the original low potential zone and pushed it down to the layer between the depth of $20 \mathrm{~cm}$ and $30 \mathrm{~cm}$, with lowest value of $-3989 \mathrm{~cm}$ water column. The rainfall increased the soil matric potential almost 9 times. At the mean time, the zero soil matric potential gradient planes moved downwards, and this was shown clearly in Fig. 5b. According to the pattern of the soil matric potential and its gradient, the soil moisture would 
transport upwards from the bottom of the soil profile during the whole period, which was accordant with Walvoord's statements (Walvoord et al., 2002).

Figure 6a shows the daily time series of soil temperature profiles, where the interval of isolines was $2^{\circ} \mathrm{C}$. The densities of isolines indicated how strongly the soil temperature at certain depth fluctuated. The dense and sparse isolines represented the rapid and slow variation of soil temperature with time, respectively. It could be found that the isolines near the surface were the densest, while the isolines at the bottom of soil profile were the sparsest. It indicated that the amplitude of soil temperature variation was reduced with depth. During the observation period, the surface temperature varied from $9.16^{\circ} \mathrm{C}$ to $63^{\circ} \mathrm{C}$, with a range of daily maximum surface temperature between $39^{\circ} \mathrm{C}$ and $63^{\circ} \mathrm{C}$, and a range of daily minimum surface temperature between $9.16^{\circ} \mathrm{C}$ and $19.6^{\circ} \mathrm{C}$. While at the depth of $50 \mathrm{~cm}$, the soil temperature varied from $25.1^{\circ} \mathrm{C}$ to $30.66^{\circ} \mathrm{C}$, with a variation span of $4.36^{\circ} \mathrm{C}$ and $3.35^{\circ} \mathrm{C}$ for the maximum and minimum soil temperature.

Figure $6 \mathrm{~b}$ shows the space-time temperature gradient field, which clearly shows how heat transport in soil controls the dependence of the temperature gradient profiles in time and space. The temperature gradients were derived from $T=\left(T_{i+1}-T_{i}\right)\left({ }^{\circ} \mathrm{C} / \mathrm{cm}\right)$, where $T_{i}$ represented the soil temperature at a depth of $i \mathrm{~cm}$. The variation of isolines in Fig. 6b was similar to that in Fig. 6a. The isolines experienced alternatively the sparseness and denseness with time elapsed on the surface, at the mean time, developed downwards from denser to sparser with depth. According to the pattern of the soil temperature and its gradient, the thermal driven soil water transport was more complicated than the matric potential driven one. The positive temperature gradient could distribute throughout the whole soil profile near the twelfth day of period; this meant that the thermal fluxes could transport soil moisture to the surface from the bottom of the soil profile. On the other hand, the negative temperature gradient could distribute throughout the whole soil profile at most of days of period. However, during the whole calculation period, most of downward thermal fluxes due to the negative temperature gradient would not transport the soil moisture on the surface to reach the bottom of the soil profile, while were retarded by the upward potential driven fluxes. The soil water fluxes are discussed in more detail in the following section.

\subsubsection{The drying fronts}

With above driving forces, the soil water flux pattern could be determined, which was subsequently used to identify the drying fronts. Figure 7 a depicted the variation of the soil water flux profiles with time elapsed. The darker color indicated the negative fluxes, which meant that the soil moisture located in the darker area would be kept in soil and not evaporated at that time. According to Fig. 7a, there were two types of darker areas: the first type of darker area occurred in the

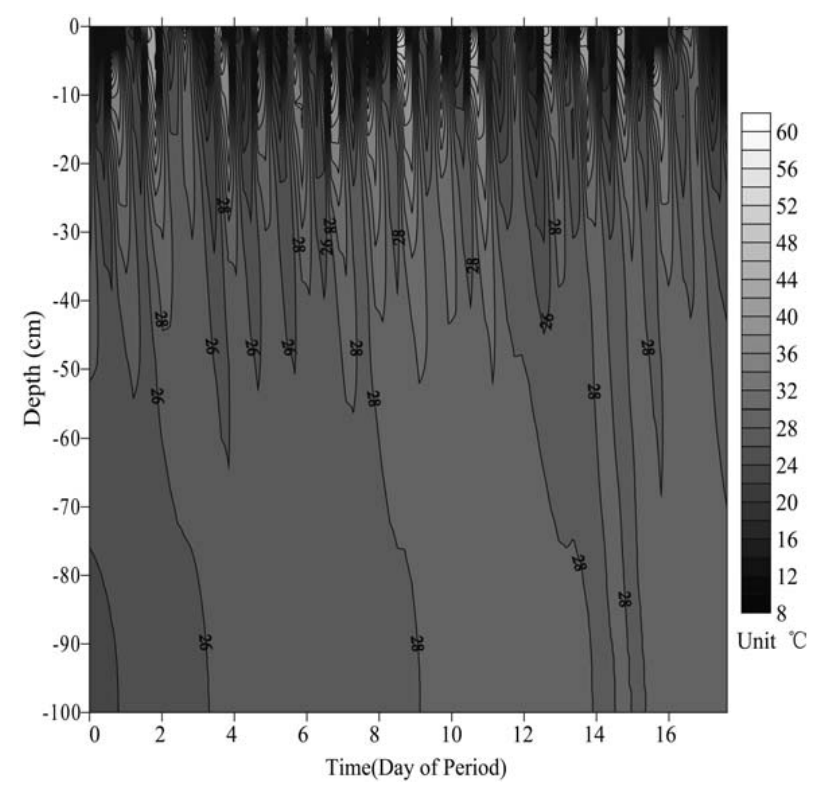

(a)

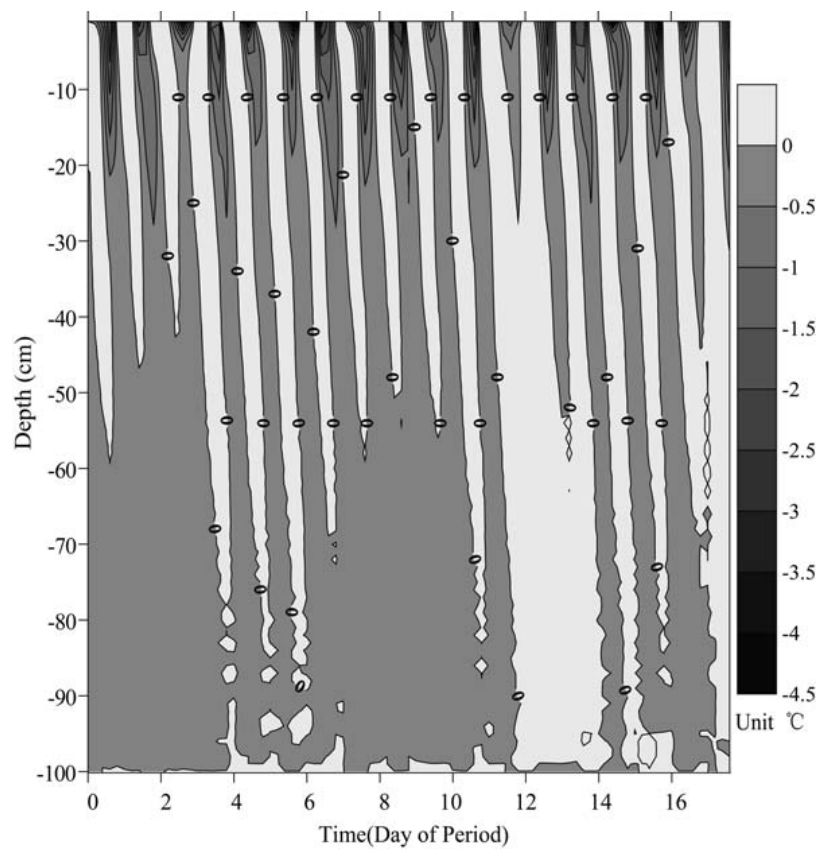

(b)

Fig. 6. The time series of soil temperature profile (a) and its gradient (b).

shallow layer limited in the depth of $45 \mathrm{~cm}$ close to surface with small time intervals and isolated shapes (A-type); the second type occurred below the depth of $45 \mathrm{~cm}$ with radical variation of the upper borderline, while the darker area kept continuity (B-type).

Almost all of the A-type and B-type darker areas were located in the negative temperature gradient zones, except 
for the darker areas triggered by the rainfall event. The isolated shapes of A-type darker areas were activated when the absolute value of the positive matric potential gradients driven fluxes were greater than the absolute value of the negative temperature gradient driven fluxes. The space gaps between the A-type and B-type areas were likewise contributed by the dominance of the positive matric potential gradients driven fluxes. Between the eighth and tenth day of the observation period, the negative temperature gradients were over the positive matric potential gradients, which lead to the connection of the A-type and B-type areas. After the rainfall, the negative matric potential gradient above the low matric potential zone (Fig. 5b) kept dominant for almost 3 days with the propagation of the zero convergent matric potential planes, from the depth of $15 \mathrm{~cm}$ to $26 \mathrm{~cm}$. The rainfall event also caused the positive temperature gradient through almost the whole depth of profile, between the twelfth and fourteenth day of the observation period. However, the soil water fluxes driven by the summation of the positive temperature gradient and matric potential gradient, during these three days, were hold back by the zero convergent matric potential planes.

The drying front could be identified by the borderlines of darker areas. On the first day of the calculation period, the drying front started from the surface due to a small A-type darker area near the surface. As time elapsed, the drying front dropped to the second A-type darker area at the depth of about $12 \mathrm{~cm}$. Since there was a gap between the second Atype darker area and the third one, which developed from the depth of $2 \mathrm{~cm}$ to $24 \mathrm{~cm}$. The drying front fell to the B-type darker area at the depth of $60 \mathrm{~cm}$ and varied in the course of time, which was corresponding to the time course occupied by the gap between the second and third A-type darker area. After this course of time for the gap, the drying front would jump to the third A-type darker area from the B-type darker area. Following the processes described above, the drying front fluctuated sharply from the surface to the upper borderlines of A-type and B-type darker areas. It should be noted that the upward fluxes underneath the lower borderlines of Atype darker areas and above the upper borderlines of B-type darker areas (the grey color area between A-type and B-type darker areas) would not be evaporated, due to the existence of convergent zero flux planes (Zeng et al., 2008) at the lower borderlines of A-type areas.

The sharp fluctuation of the drying front was interrupted by the occurrence of precipitation, which could be observed clearly in Fig. 7a. After the rainfall of $6.604 \mathrm{~mm}$, the drying front was limited at the depth of $20 \mathrm{~cm}$ for 3 days, from the eleventh to fourteenth day of the period. Then, the drying front experienced the wide fluctuation between the Atype and B-type darker areas again. It meant that the upward soil moisture flux above the upper borderlines of the B-type darker areas was kept at the lower borderlines of the A-type darker areas during these three days, and increased the moisture content near the borderlines.

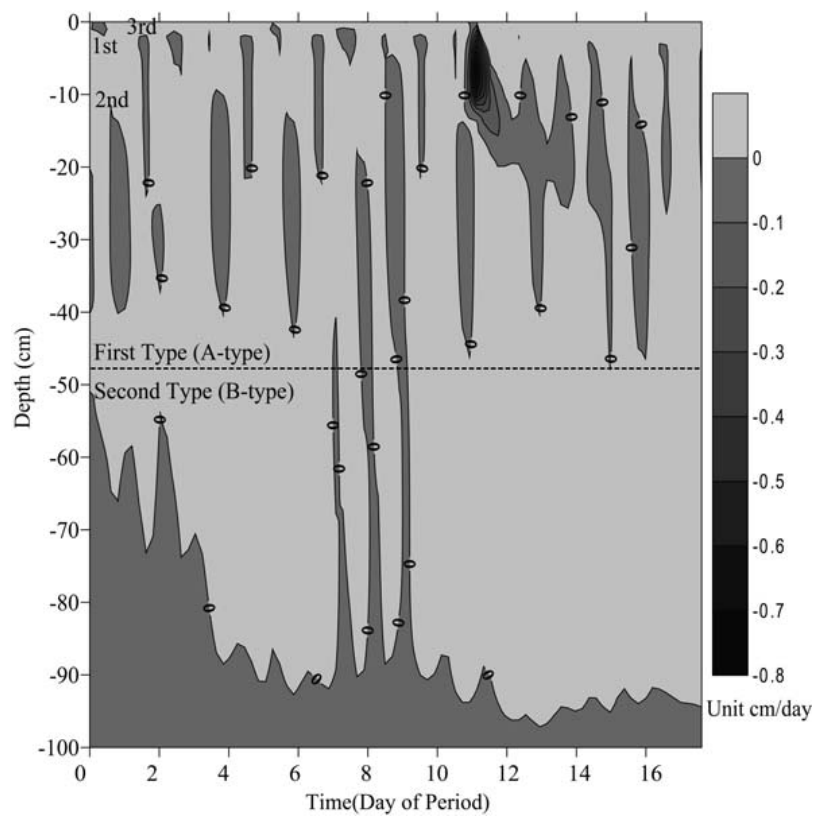

(a)

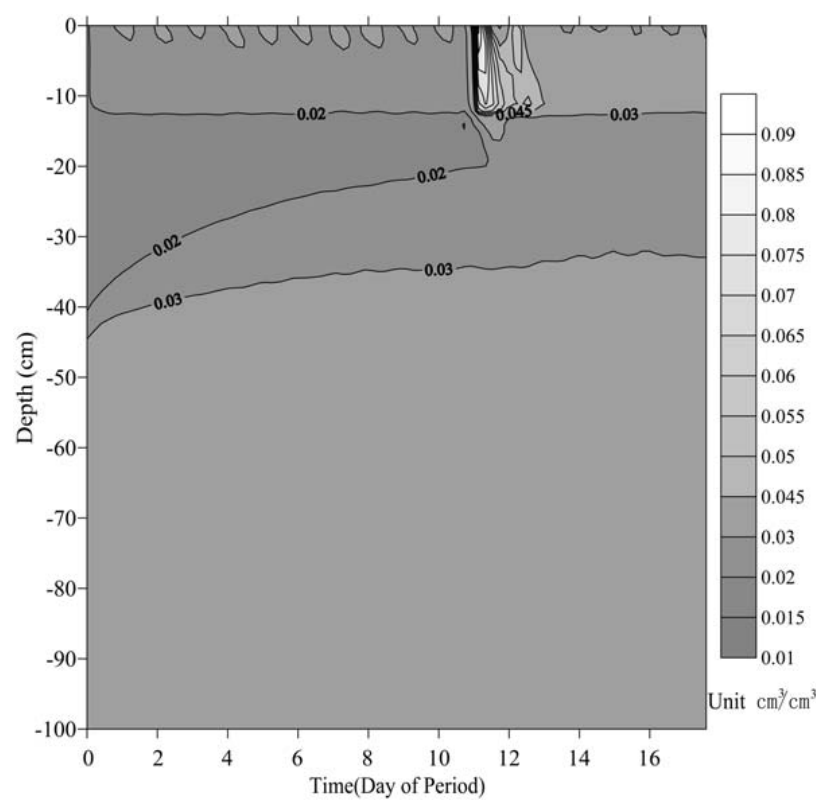

(b)

Fig. 7. The time series of soil moisture flux pattern (a) and volumetric soil moisture content pattern (b).

The corresponding variation of soil moisture profile was shown in Fig. 7b. On the day before the rainfall, due to the sharp fluctuation of the drying front, the moisture content at the depth of $10 \mathrm{~cm}$ and $20 \mathrm{~cm}$ were kept between the value of 0.017 and $0.021 \mathrm{~cm}^{3} / \mathrm{cm}^{3}$, and 0.0201 and $0.0216 \mathrm{~cm}^{3} / \mathrm{cm}^{3}$, respectively. After the rainfall, the interruption of the fluctuation of drying front increased the moisture at the depth of 
$10 \mathrm{~cm}$ and $20 \mathrm{~cm}$ to 0.065 and $0.0256 \mathrm{~cm}^{3} / \mathrm{cm}^{3}$, respectively. However, the moisture content at the depth of 30,40 , and $50 \mathrm{~cm}$ were not influenced directly by the rainfall event. After the stop of the rainfall, the moisture content at the depths of $10 \mathrm{~cm}$ and $20 \mathrm{~cm}$ decreased with time due to the propagation of the drying fronts. When the connected A-type areas were separated due to increasing evaporation, the moisture content at the depths of $10 \mathrm{~cm}$ and $20 \mathrm{~cm}$ would go back to the value before the rainfall gradually.

From above discussion, the $6.604 \mathrm{~mm}$ of rainfall could not be remained in sand, and would be evaporated to the atmosphere after some course of time. But, the rainfall interrupted the fluctuation of the drying front and made the isolated Atype darker areas connected for 3 days, which subsequently limited the upwards soil water flux from the deeper sand layer. All these kept the sand moister than before the rainfall in the shallow layer close to the surface (surface to the depth of $20 \mathrm{~cm}$ ). Furthermore, at the end of the calculation period, seven days after the rainfall, the moisture content at the depth of $10 \mathrm{~cm}$ was $0.036 \mathrm{~cm}^{3} / \mathrm{cm}^{3}$, which was $0.015 \mathrm{~cm}^{3} / \mathrm{cm}^{3}$ higher than its daily averaged value for the days before the rainfall. However, the $6.604 \mathrm{~mm}$ of rainfall was not enough to penetrate into the B-type darker area, which would keep the soil moisture in soil and form the effective infiltration. It should be noted that the effective infiltration requires the rainfall penetrating below the deepest drying front, for example, in this case, under the depth of $94 \mathrm{~cm}$ (Fig. 7a).

\subsection{Determination of effective infiltration}

After the rainfall, the infiltrating process will form a downward wetting front in soil. When the rainfall stops, the evaporation on the surface would dry the wetted soil and form a drying front. During the redistribution of the infiltrated rainfall, the drying front chases the wetting front. If the infiltrated rainfall could not penetrate into the deepest drying front before the stop of redistributing process and be caught up by the drying front, there would be no effective infiltration in sand. On the other hand, if the rainfall does penetrate below the deepest drying front, the volume of this part of rainfall could be determined by the calculation of the cumulative infiltration below the deepest drying front, which can be identified by the HYDRUS with field data. With the HYDRUS, the volumetric soil moisture could be retrieved with a spatial resolution of $1 \mathrm{~cm}$, which helps us to know exactly when and where the redistribution of infiltrated rainfall stops. The cumulative infiltration below the deepest drying front could be determined by the difference of the volumetric soil moisture profiles before and after the redistribution, which could be described as

$$
\begin{aligned}
& R_{\text {eff }}=\bar{\theta}_{\text {wetted }}-\bar{\theta}_{\text {original }}, \\
& \bar{\theta}=\sum_{i=1}^{n}\left(\frac{\theta_{i}+\theta_{i+1}}{2}\right) \Delta z, i=1,2,3, \ldots \ldots n
\end{aligned}
$$

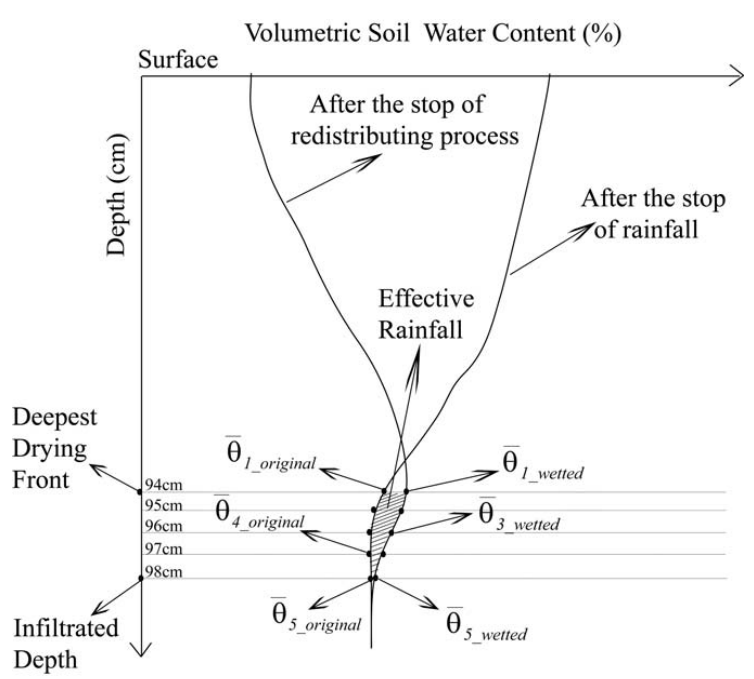

Fig. 8. The schematic map of the calculation of the effective infiltration.

where $R_{\text {eff }}$ is the effective infiltration, $\bar{\theta}_{\text {wetted }}$ is the average volume of soil moisture after the redistribution, $\bar{\theta}_{\text {original }}$ is the average volume of soil moisture before the redistribution, $\theta_{i}$ and $\theta_{i+1}$ are the volumetric soil moistures below the deepest drying front with an interval of $\Delta z$, and $n$ is determined by the difference between the deepest drying front and the infiltrated depth [(the depth of deepest drying front the infiltrated depth) $/{ }^{\Delta} z$ ]. For example, in the case of the deepest drying front of $94 \mathrm{~cm}$, if the infiltrated depth was $98 \mathrm{~cm}$ and the interval $(\Delta z)$ was set as $1 \mathrm{~cm}$, the $n$ would be equal to $4((98 \mathrm{~cm}-94 \mathrm{~cm}) / 1 \mathrm{~cm})$; while, $\theta_{1}, \theta_{2}, \theta_{3}, \theta_{4}$ and $\theta_{5}$ would be the volumetric moisture content at the depth of $94,95,96$, 97, and $98 \mathrm{~cm}$ (Fig. 8).

The precipitation of $6.604 \mathrm{~mm}$ was not enough to penetrate into the deepest drying front in this case. In order to have an idea on how much volume of rainfall could penetrate into sand and became the effective infiltration, the volume of precipitation was set as $33.02 \mathrm{~mm}$ with a rainfall rate of $6.6 \mathrm{~mm} / \mathrm{hr}$ ( $\mathrm{Li}$ et al., 2006; Wang et al., 2007). According to the calculation result, the rainfall penetrated to the depth of $98 \mathrm{~cm}$. The original volumetric soil moisture content at the depth of $94,95,96,97$, and $98 \mathrm{~cm}$ were $0.0429,0.043,0.0432,0.0433$, and $0.0434 \mathrm{~cm}^{3} / \mathrm{cm}^{3}$, respectively, while they became $0.0465,0.0459,0.0455,0.045$ and $0.0445 \mathrm{~cm}^{3} / \mathrm{cm}^{3}$ after the stop of redistribution. According to the Eq. (12), the effective infiltration was $0.0925 \mathrm{~mm}$.

\section{Conclusions}

The effective infiltration is defined here as the amount of rainfall remained in sand beneath the deepest drying front from an incident rainfall event. In order to understand the effective infiltration, the coupled liquid water, vapor and heat 
transport in sand was analyzed to determine the drying front by using the HYDRUS code. According to the calculation results, the drying fronts were mainly determined by the shapes of the zero flux isolines. There were two kinds of shapes of zero flux isolines: A-type, which occurred in the shallow layer limited in the depth of $45 \mathrm{~cm}$ close to surface with small time intervals and isolated shapes, and B-type, which occurred below the depth of $45 \mathrm{~cm}$ with a radical variation (from the depth of 45 to $94 \mathrm{~cm}$ ) and kept the continuity. Consequently, the drying front fluctuated sharply during the whole calculation period. The rainfall interrupted the fluctuation of the drying front and kept it in the depth of $20 \mathrm{~cm}$ for 3 days. Although, the $6.604 \mathrm{~mm}$ of rainfall could not penetrate into the deepest drying front during the whole period, it did keep sand moister than before rainfall in the shallow layer close to the surface (surface to the depth of $20 \mathrm{~cm}$ ). Based on the HYDRUS code, a simple method was used to estimate the effective infiltration. With the artificially set rainfall of $33.02 \mathrm{~mm}$ and the rainfall rate of $6.6 \mathrm{~mm} / \mathrm{hr}$, the effective infiltration was estimated as $0.0925 \mathrm{~mm}$.

Considering the maximum annual precipitation of $120 \mathrm{~mm}$ in the Badain Jaran Desert, simply multiplying the estimated effective infiltration with a factor of $3.6(120 \mathrm{~mm} / 33.02 \mathrm{~mm})$, the value of $0.336 \mathrm{~mm} / \mathrm{yr}$ was lower than the historic records based on hydrochemical and isotopic methods, which was from 0.95 to $3.6 \mathrm{~mm} / \mathrm{yr}$. In fact, the annual precipitation of $120 \mathrm{~mm}$ would not be simply characterized by about four single rainfalls, each of which was of $33.02 \mathrm{~mm}$ with the rainfall rate of $6.6 \mathrm{~mm} / \mathrm{hr}$. The actual annual effective infiltration was possibly lesser in the Badain Jaran Desert. The characteristics of individual rainfall events, such as the amount, the density, and the duration, and the variation pattern of the drying front, would affect the infiltrating and redistributing process in soil and thus the effective infiltration. Furthermore, the annual spatial and temporal variation pattern of the precipitation played a critical role in determining the effective infiltration. In order to understand the effective infiltration in the Badain Jaran Desert, a long-term observation should be established.

Acknowledgements. The research projects on which this paper is based were funded by the National Natural Science Foundation of China (Grant Nr. 90302003), the CAS International Partnership Project "The Basic Research for Water Issues of Inland River Basin in Arid Region" (Grant Nr. CXTD-Z2005-2)", and "The ESAMOST Dragon Programme" and by the European Commission (Call FP7-ENV-2007-1 Grant nr. 212921) as part of the CEOP AEGIS project (http://www.ceop-aegis.org/) coordinated by the Université Louis Pasteur. We thank the anonymous referees very much for their helpful and constructive comments and suggestions for improving the manuscript. We have a deep desire of acknowledgement for the help of Hirotaka Saito and Masaru Sakai on the guide of using HYDRUS.

Edited by: J. Wen

\section{References}

Bonacci, O., Jukic, D., and Ljubenkov, I.: Definition of catchment area in karst: case of the rivers Krcic and Krka, Croatia, Hydrolog. Sci. J., 51, 682-699, 2006.

Brutsaert, W.: Evaporation into the atmosphere: Theory, history, and applications, D. Reidel Publ., Dordrecht, the Netherlands, 299 pp., 1982.

Camillo, P. J. and Gurney, R. J.: Resistance Parameter for Bare-Soil Evaporation Models, Soil Science SOSCAK, 141, 95-105, 1986.

Chen, J. S., Li, L., Wang, J. Y., Barry, D. A., Sheng, X. F., Gu, W. Z., Zhao, X., and Chen, L.: Water resources - Groundwater maintains dune landscape, Nature, 432, 459-460, 2004.

Dong, Z. B., Wang, T., and Wang, X. M.: Geomorphology of the megadunes in the Badain Jaran desert, Geomorphology, 60, 191203, 2004.

Fares, A. and Polyakov, V.: Advances in crop water management using capacitive water sensors, Adv. Agron., 90, 43-77, 2006.

Fares, A., Hamdhani, H., and Jenkins, D. M.: Temperaturedependent scaled frequency: Improved accuracy of multisensor capacitance probes, Soil Sci. Soc. Am. J., 71, 894-900, 2007.

Gates, J. B., Edmunds, W. M., and Ma, J. Z.: Groundwater recharge rates to the Badain Jaran Desert: preliminary results from environmental tracer studies, the 34th congress of international association of hydrogeologists, Beijing, China, 9-13 October 2006, 311, 2006.

Gates, J. B., Edmunds, W. M., and Ma, J. Z.: Estimating groundwater recharge in a cold desert environment in northern China using chloride, Hydrogeol. J., 16, 893-910, 2008a.

Gates, J. B., Bohlke, J. k., Edmunds, W. M.: Ecohydrological factors affecting nitrate concentrations in a phreatic desert aquifer in northwestern China, Environ. Sci. Technol., 42, 3531-3537, 2008 b.

Geiger, S. L. and Durnford, D. S.: Infiltration in homogeneous sands and a mechanistic model of unstable flow, Soil Sci. Soc. Am. J., 64, 460-469, 2000.

Geyh, M. A., Gu, W. Z., and Jakel, D.: Groundwater recharge study in the Gobi Desert, China, Geowissenschaften, 14, 279280, 1996.

Ghildyal, B. P. and Tripathi, R. P.: Soil Physics, Rajkamal Electric Press, India, 1-656, 1987.

Gu, W. Z., Seiler, K. P., Stichler, W., and Lu, J. J.: Groundwater recharge in the badain jaran shamo, inner mongolia, PR China, the 34th congress of international association of hydrogeologists, Beijing, China, 9-13 October 2006, 507 pp., 2006.

Hofmann, J.: Lakes in the SE part of Badain Jaran Shamo, their limnology and geochemistry, Geowissenschaften, 14, 275-278, 1996.

Hofmann, J.: Geo-ecological investigations of the waters in the south-eastern Badain Jaran Desert, in: Status und spätquartäre Gewässerentwicklung, Berliner Geogr. Abh. 64, Habilitationsschrift, Berlin, 1-164, 1999

Jakel, D.: The Badain Jaran Desert: its origin and development, Geowissenschaften, 14, 272-274, 1996.

Li, S. Z., Xiao, H. L., Cheng, G. D., Luo, F., and Liu, L. C.: Mechanical disturbance of microbiotic crusts affects ecohydrological processes in a region of revegetation-fixed sand dunes, Arid Land Res. Manag., 20, 61-77, 2006.

Lu, N., and Likos, W. J.: Unsaturated soil mechanics, John Wiley\&Sons, Inc., Hoboken, USA, 584 pp., 2004. 
Ma, J. Z., Li, D., Zhang, J. W., Edmunds, W. M., and Prudhomme, C.: Groundwater recharge and climatic change during the last 1000 years from unsaturated zone of SE Badain Jaran Desert, Chinese Sci. Bull., 48, 1469-1474, 2003.

Ma, J. Z., and Edmunds, W. M.: Groundwater and lake evolution in the Badain Jaran desert ecosystem, Inner Mongolia, Hydrogeol. J., 14, 1231-1243, 2006.

Melone, F., Corradini, C., Morbidelli, R., and Saltalippi, C.: Laboratory experimental check of a conceptual model for infiltration under complex rainfall patterns, Hydrol. Process., 20, 439-452, 2006.

Mitkov, I., Tartakovsky, D. M., and Winter, C. L.: Dynamics of wetting fronts in porous media, Phys. Rev. E, 58, R5245-R5248, 1998.

Noborio, K., McInnes, K. J., and Heilman, J. L.: Measurements of cumulative infiltration and wetting front location by time domain reflectometry, Soil Sci., 161, 480-483, 1996.

NJHRI: Specification of soil test (SL 237-1999), China Water Power press, Beijing, China, 757 pp., 1999

Philip, J. R. and De Vries, V. D.: Moisture movement in porous materials under temperature gradient, Trans. Am. Geophys. Union, 38, 222-232, 1957.

Polyakov, V., Fares, A., and Ryder, M. H.: Calibration of a capacitance system for measuring water content of tropical soil, Vadose Zone Journal, 4, 1004-1010, 2005.

Saito, H., Simunek, J., and Mohanty, B. P.: Numerical analysis of coupled water, vapor, and heat transport in the vadose zone, Vadose Zone Journal, 5, 784-800, 2006.

Scanlon, B. R., Keese, K., Reedy, R. C., Simunek, J., and Andraski, B. J.: Variations in flow and transport in thick desert vadose zones in response to paleoclimatic forcing (0-90 kyr): Field measurements, modeling, and uncertainties, Water Resour. Res., 39(7), 1179, doi:10.1029/2002WR001604, 2003

Hukseflux Themal Sensors.: Soil temperature profile sensor user manual (version 0606), Delft, the Netherlands, available at: http: //www.hukseflux.com/, 2007.

Sentek Pty. Ltd.: Calibration of Sentek Pty Ltd soil moisture sensors, Stepney, SA, Australia, available at: http://www.sentek. com.au/home/default.asp, 2001.

Shigeru, O., Yosuke, K., and Ayumi, Y.: Studies on the infiltrationdischarge of rain water and translation penomena in soil, J. Hydrol., 132, 1-23, 1992.

Golden Software: Surfer Reference Manual. Version, 4 edn., Golden, CO., http://www.goldensoftware.com/, 1990.

Tami, D., Rahardjo, H., and Leong, E. C.: Effects of hysteresis on steady-state infiltration in unsaturated slopes, J. Geotech. Geoenviron., 130, 956-967, 2004

Timlin, D. and Pachepsky, Y.: Infiltration measurement using a vertical time-domain reflectometry probe and a reflection simulation model, Soil Sci., 167, 1-8, 2002.
Topp, G. C., Davis, J. L., and Annan, A. P.: Electromagnetic determination of soil water content using TDR: I. applications to wetting fronts and steep gradients, Soil Sci. Soc. Am. J., 46, 672 678, 1982.

van Bavel, C. H. M. and Hillel, D. I.: Calculating potential and actual evaporation from a bare soil surface by simulation of concurrent flow of water and heat, Agric. For. Meteorol. J., 17, 453-476, 1976.

van Genuchten, M. T.: A closed-form equation for predicting the hydraulic conductivity of unsaturated soils, Soil Sci. Soc. Am. J, 44, 892-898, 1980.

Walker, A. S., Olsen, J. W., and Bagen: The Badain Jaran Desert: Remote sensing investigations, Geogr. J., 153, 205-210, 1987.

Walvoord, M. A., Plummer, M. A., Phillips, F. M., and Wolfsberg, A. V.: Deep arid system hydrodynamics, 1. Equilibrium states and response times in thick desert vadose zones, Water Resour. Res, 8(12), 1308, doi:10.1029/2001WR000824, 2002.

Wang, G. X. and Cheng, G. D.: Water resource development and its influence on the environment in arid areas of China - the case of the Hei River basin, J. Arid. Environ., 43, 121-131, 1999.

Wang, X. P., Li, X. R., Xiao, H. L., Berndtsson, R., and Pan, Y. $X .:$ Effects of surface characteristics on infiltration patterns in an arid shrub desert, Hydrol. Process., 21, 72-79, 2007.

Wang, X. P., Cui, Y., Pan, Y. X., Li, X. R., Yu, Z., and Young, M. H. Effects of rainfall characteristics on infiltration and redistribution patterns in revegetation-stabilized desert ecosystems, J. Hydrol., 358, 134-143, 2008.

Wu, J. Q., Zhang, R. D., and Yang, J. Z.: Estimating infiltration recharge using a response function model, J. Hydrol., 198, 124 139, 1997.

Yang, H., Rahardjo, H., Wibawa, B., and Leong, E. C.: A soil column apparatus for laboratory infiltration study, Geotech. Test. J., 27, 347-355, 2004

Yang, H., Rahardjo, H., and Leong, E. C.: Behavior of unsaturated layered soil columns during infiltration, J. Hydrol. Eng., 11, 329 337, 2006.

Yang, X. P.: Landscape evolution and palaeoclimate in the deserts of northwestern China, with a special reference to Badain Jaran and Taklamakan, Chinese Sci. Bull., 46, 6-11, 2001.

Yang, X. P., Liu, T. S., and Xiao, H. L.: Evolution of megadunes and lakes in the Badain Jaran Desert, Inner Mongolia, China during the last 31000 years, Quatern. Int., 104, 99-112, 2003a.

Yang, X. P. and Williams, M. A. J.: The ion chemistry of lakes and late Holocene desiccation in the Badain Jaran Desert, Inner Mongolia, China, Catena, 51, 45-60, 2003b.

Yang, X. P.: Chemistry and late Quaternary evolution of ground and surface waters in the area of Yabulai Mountains, western Inner Mongolia, China, Catena, 66, 135-144, 2006.

Zeng, Y., Wan, L., Su, Z., Saito, H., Huang, K., and Wang, X.: Dirnal soil water dynamics in the shallow vadose zone, Environ. Geol., doi:10.1007/s00254-008-1485-8, 2008.

Zhang, H. C. and Ming, Q. Z.: Hydrology and Lake Evolution in Hyperarid Northwestern China and the Mystery of Megadune Formation in Badain Jaran Desert, Advances in Earth Science, 21, 532-538, 2006 (in Chinese). 